\title{
Microscopic Findings Distribution
}

National Cancer Institute

\section{Source}

National Cancer Institute. Microscopic Findings Distribution. NCI Thesaurus. Code

C124035.

The placement, arrangement or instance of microscopic findings within an anatomical space. 